\title{
Evaluasi Perbaikan Tanah Menggunakan Rapid Impact Compaction pada Tanah Berpotensi Likuefaksi
}

\author{
Desti Santi Pratiwi \\ Teknik Sipil, Fakultas Teknik Sipil dan Perencanaan, Institut Teknologi Nasional Bandung \\ Email: destisantipratiwi@itenas.ac.id
}

Received 30 April $2020 \mid$ Revised 27 Juni 2020 | Accepted 29 Juni 2020

\begin{abstract}
ABSTRAK
Rapid Impact Compaction (RIC) merupakan salah satu metode perbaikan tanah secara mekanik untuk tanah granular. Prinsip dasar dari Rapid Impact Compaction yaitu menjatuhkan beban hammer dengan tinggi jatuh yang relatif rendah dengan kecepatan yang tinggi. RIC dapat dijadikan alternatif dalam mitigasi likuefaksi. Beberapa penelitian sebelumnya menyatakan bahwa RIC dapat memperbaiki tanah hingga kedalaman $6 \mathrm{~m}$. Pada penelitian ini, evaluasi efektifitas perbaikan tanah menggunakan RIC dilakukan di lokasi Pembangunan New Yogyakarta International Airport Kulon Progo. Pada lokasi tersebut terdapat tanah pasir lepas dan berpotensi likuefaksi hingga kedalaman 8m. Analisis yang dilakukan yaitu membandingkan nilai Standard Penetration Test (SPT) sebelum dan setelah perbaikan tanah dengan RIC. Hasil analisis menunjukkan bahwa terdapat kenaikan nilai SPT sebesar $10-12$, sehingga dapat memehuni kriteria desain yang telah ditentukan untuk mitigasi likuefaksi.
\end{abstract}

Kata kunci: perbaikan tanah, likuefaksi, Rapid Impact Compaction, SPT.

\begin{abstract}
Rapid Impact Compaction (RIC) is one of mechanical ground improvement technique that suitable for granular soil material. The principle of this method is repeatedly strike an impact plate on the ground surface using a hydraulic hammer. RIC can be implemented as an alternative for liquefaction mitigation. Some previous studies have stated that RIC can improve the soil to a depth of $6 \mathrm{~m}$. The evaluation of effectiveness RIC to improving problematic soil was taken in New Yogyakarta International Airport project. At the project site, the soil condition is consist of loose sand and potential to be liquefied up to 8 $m$ depth. The analysis has donne by comparing the SPT value before and after improving by RIC. The result of analysis gave an information that there is an increace SPT value of $10-12$, so it can meet with the design criteria for mitigation of liquefaction.
\end{abstract}

Keywords: ground improvement, liquifaction, Rapid Impact Compaction, SPT. 


\section{PENDAHULUAN}

Rapid Impact Compaction (RIC) merupakan salah satu metode pemadatan tanah dinamis dengan cara menumbuk tanah menggunakan hammer sehingga dapat meningkatkan daya dukung tanah. Prinsip dari metode ini yaitu menjatuhkan beban hammer dari ketinggian yang relatif rendah dengan kecepatan tinggi [1]. Pada alat RIC terdapat kaki baja yang tetap terhubung secara permanen pada tanah sebagai media penyalur tumbukan dari hammer.

Berat hammer pada RIC umumnya sebesar 5 - 12 ton, dimana dijatuhkan dari ketinggian $1.2 \mathrm{~m}$ pada kaki baja berbentuk lingkaran dengan diameter $1.0-1.5 \mathrm{~m}$ (yang paling umum adalah $1.5 \mathrm{~m}$ ). Pemadatan menggunakan RIC dapat menghasilkan 40 - 60 tumbukan per menit, sehingga dapat melebihi kecepatan mesin Dynamic Compaction (DC). Kedalaman perbaikan tanah dengan menggunakan RIC tergantung dari jenis dan propertis geomaterial, letak muka air tanah, dan energi yang dipakai. Tingkat produksi mesin RIC dapat mencapai $500 \mathrm{~m}^{2}$ per hari [2]. Pemantauan data selama proses pemadatan ditampilkan secara langung (online) di kabin operator yang dapat memungkinkan mengontrol pemadatan, pengaplikasian ekonomis alat pemadatan, dan mengatur kualitas pekerjaan. Alat akan berhenti apabila telah memenuhi persyaratan seperti kedalaman total perbaikan, jumlah tumbukan, dan penurunan total akhir dari tumbukan [3].

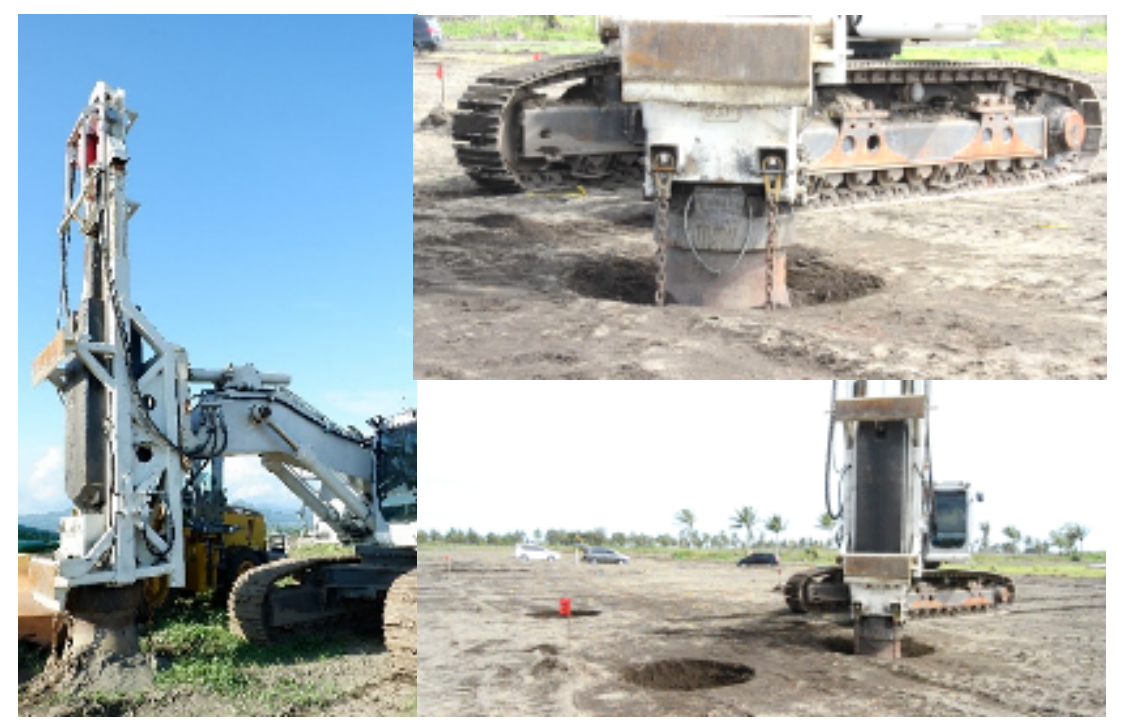

Gambar 1. Alat RIC (kiri), impact foot dengan driving cap (kanan atas), dan proses pemadatan (kanan bawah) [4]

Metode RIC ini cocok digunakan untuk material granular, termasuk kerikil, pasir, lanau, timbunan yang tidak terkontrol, dan limbah industri atau tambang [2]. RIC dapat memadatkan tanah yang lepas hingga kedalaman 4-6 m [5]. Metode RIC ini dapat digunakan untuk memperbaiki daya dukung tanah dan mengurangi potensi likuefaksi pada tanah lepas.

Likuefaksi terjadi ketika tekanan air pori pada kedalaman geomaterial pasir sama dengan tegangan totalnya, sehingga tegangan efektif sama dengan nol. Tekanan air pori meningkat disebabkan oleh kecenderungan material granular untuk memadat ketika mengalami deformasi geser siklik. Akibatnya, tanah akan kehilangan kekuatannya dan menyebabkan deformasi yang besar dan bahkan kegagalan struktur di atasnya maupun struktur di bawah tanah sehingga dapat memakan korban. Ketika terjadi likuefaksi, tanah akan berubah sifat menjadi cair. Ketika pencairan terjadi, lapisan tanah menjadi lunak, sehingga memungkinkan terjadinya deformasi siklik cukup besar sehingga dapat membahayakan bangunan yang berdiri di atasnya. Oleh karena itu perlu upaya dalam pencegahan likuefaksi [2]. 
Kemungkinan potensi likuefkasi dapat ditentukan dengan dua pendekatan, yaitu pengujian laboratorium pada tanah tidak terganggu dan penggunaan hubungan emipiris berdasarkan korelasi peprilaku tanah di lapangan yang diamati dengan berbagai indeks tes di lapangan [6].

Maksud dari penelitian ini adalah melakukan perbandingan kondisi tanah berpotensi likuefaksi sebelum dan setelah perbaikan tanah menggunakan metode Rapid Impact Compaction berdasarkan hasil pengujian di lapangan berupa Pengujian SPT. Tujuan dari penelitian ini yaitu mengevaluasi keefektifan Rapid Impact Compaction sebagai metode perbaikan tanah berpotensi likuiefaksi di lokasi pembangunan New Yogyakarta International Aiport (NYIA) di Kulon Progo Provinsi Yogyakarta.

\section{METODOLOGI}

\subsection{Lokasi Penelitian}

Lokasi penelitian yang akan ditinjau yaitu area pembangunan bandara New Yogyakarta International Airport di Kulon Progo Provinsi Yogyakarta. Berdasarkan pengamatan visual dan penyelidikan tanah di lapangan, didapatkan bahwa tanah di lokasi tersebut merupakan tanah pasir lepas sehingga memiliki daya dukung yang rendah dan berpotensi terlikuefaksi. Metode perbaikan tanah yang dilakukan di lapangan yaitu Dynamic Compaction dan Rapid Impact Compaction. RIC digunakan pada area landside atau area terminal. Denah pekerjaan bandara di tunjukkan pada di bawah ini.

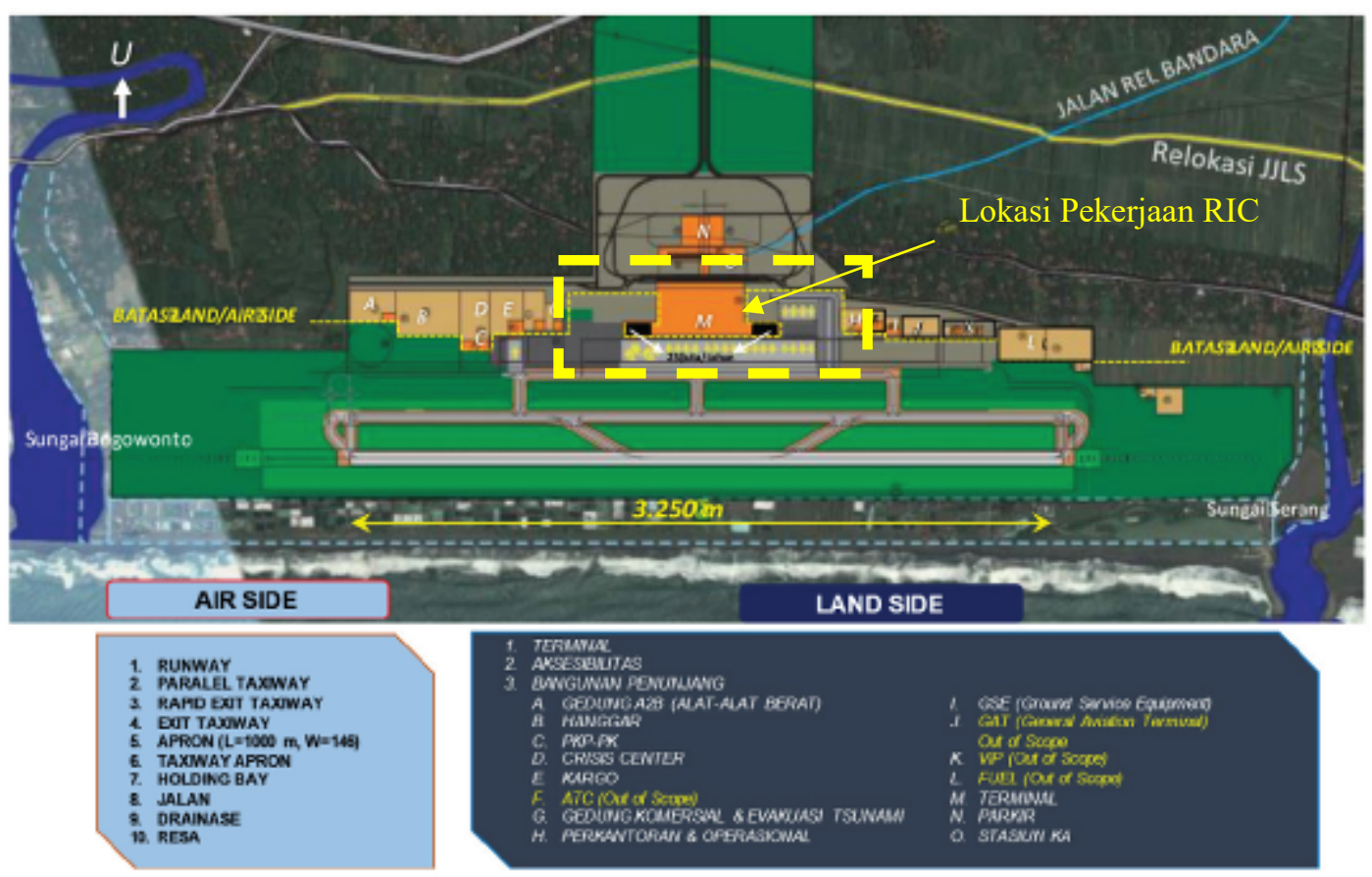

Gambar 2. Denah pekerjaan bandara [7]

\subsection{Kondisi Tanah di Lokasi Penelitian}

Kondisi tanah di lokasi pekerjaan, sebelum adanya perbaikan tanah menunjukkan karakteristik pasir lepas dan memiliki muka air tanah yang tinggi sehingga apabila terjadi gempa akan terjadi bahaya likuefaksi. Pada Gambar 3 dapat dilihat kondisi tanah pasir di lokasi pekerjaan. 


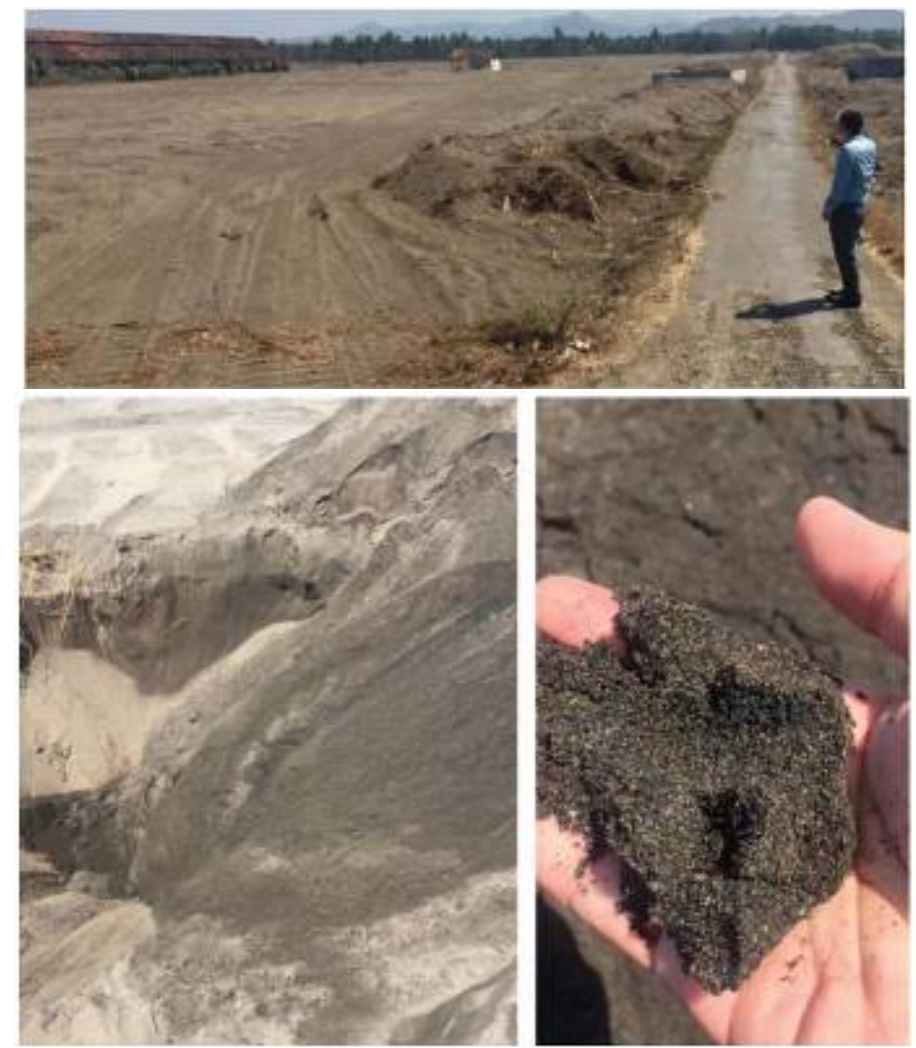

Gambar 3. Kondisi tanah di lokasi pembangunan NYIA [7]

Pada area terminal telah dilakukan penyelidikan tanah di lapangan, yaitu berupa pengujian bor dalam dan uji CPT. Pengujian bor dalam yang dilakukan, yaitu berupa uji SPT dan pengambilan sampel tanah yang akan diuji laboratorium. Pengujian SPT bertujuan untuk mengetahui kekuatan tanah berdasarkan nilai SPT (N-SPT), yang nantinya akan digunakan untuk analisis. Pengujian SPT sebelum perbaikan tanah (pre-RIC) dilakukan sebanyak sepuluh titik menyebar di area terminal yang ditunjukkan pada Gambar 4.

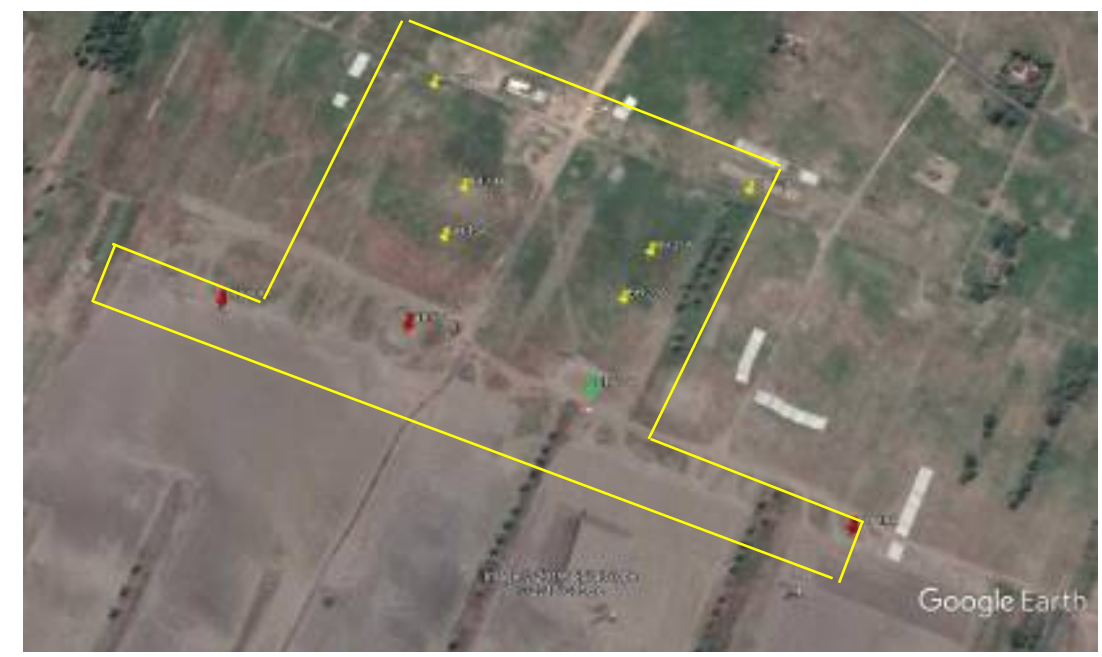

Gambar 4. Lokasi pekerjaan pemboran mesin pre - RIC di area darat pembangunan NYIA

Dari hasil pengujian bor dalam sebanyak sepuluh titik di area terminal didapatkan borlog dengan ratarata lapisan tanah seperti yang disajikan pada Tabel 1. Rata-rata kedalaman lapisan pasir lepas dengan 
nilai SPT di bawah 20 berada pada kedalaman $0-4 \mathrm{~m}$. Borlog hasil pengujian bor dalam yang mewakili kedalaman tanah pasir lepas $0-4$ m ditunjukan pada borlog $\mathrm{BH}-13 \mathrm{~A}$ (Gambar 4).

Tabel 1. Rata-rata Profil Lapisan Tanah NYIA di Area Terminal [7]

\begin{tabular}{cccc}
\hline \multicolumn{2}{c}{ Kedalaman } & Deskripsi \\
\hline 0 & - & 2 & Pasir halus \\
2 & - & 4 & Pasir halus sedang \\
4 & - & 8 & Pasir sedang - keras \\
8 & - & 10 & Pasir keras \\
\hline
\end{tabular}

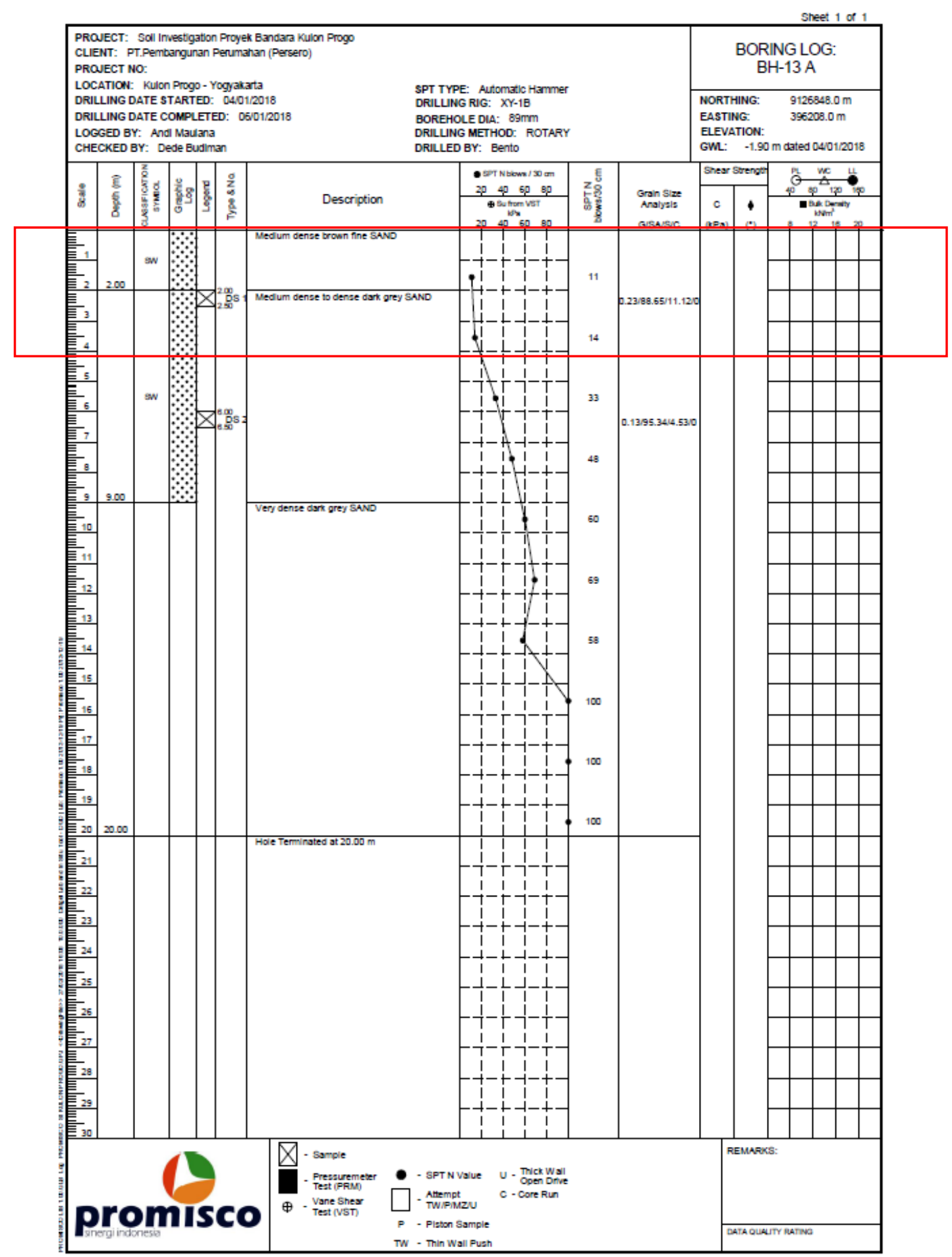

Gambar 4. Borlog BH - 13 A di area terminal [8]

Rekayasa Hijau - 86 


\subsection{Kriteria Desain}

Pada pekerjaan pembangunan bandara ini, telah dibuat sebuah kriteria desain berupa nilai parameter tanah minimum agar tanah tidak berpotensi mengalami likuefaksi. Nilai faktor keamanan (FK) yang digunakan sebagai syarat minimum yakni sebesar 1.3. Kriteria desain minimum yang digunakan yaitu berdasarkan dari nilai SPT, qc dan Dr (\%), adapun tabel kriteria desain yang ditunjukan pada Tabel 2.

Tabel 2. Kriteria Parameter Desain [9]

\begin{tabular}{cccc}
\hline Kedalaman & N-SPT & $\mathbf{Q}_{\mathbf{c}}$ (Mpa) & Dr (\%) \\
\hline 2 & 16 & 7 & $>70$ \\
4 & 22 & 9 & $>70$ \\
6 & 26 & 13 & $>70$ \\
8 & 30 & 15 & $>70$ \\
\hline
\end{tabular}

\subsection{Perbaikan Tanah Menggunakan RIC}

Metode Rapid Impulse Compaction (RIC) bekerja dengan menjatuhkan beban hammer berulang kali pada tanah permukaan dengan tinggi jatuh beban hammer yang relatif rendah sehingga memungkinkan untuk melakukan penumbukan berulang dengan waktu yang cepat. Jarak antar titik tumbukan juga tergolong rapat dibandingkan dengan metode Dynamic Compaction [10].

Metode ini digunakan untuk meningkatkan kepadatan, kekuatan dan kekakuan tanah, serta mengurangi potensi deformasi, permeabilitas, keruntuhan, ground heaving dan likuefaksi. Berbeda dengan Roller Compaction, metode ini cocok untuk materi tanah granular hingga kedalaman $6 \mathrm{~m}$. Metode ini digunakan untuk memadatkan tanah subgrade, tanah untuk pondasi, dan timbunan [10]. Sehingga metode ini digunakan untuk memadatkan tanah pada area terminal. Alat Rapid Impact Compaction yang digunakan di lapangan ditunjukkan pada Gambar 5 di bawah ini.

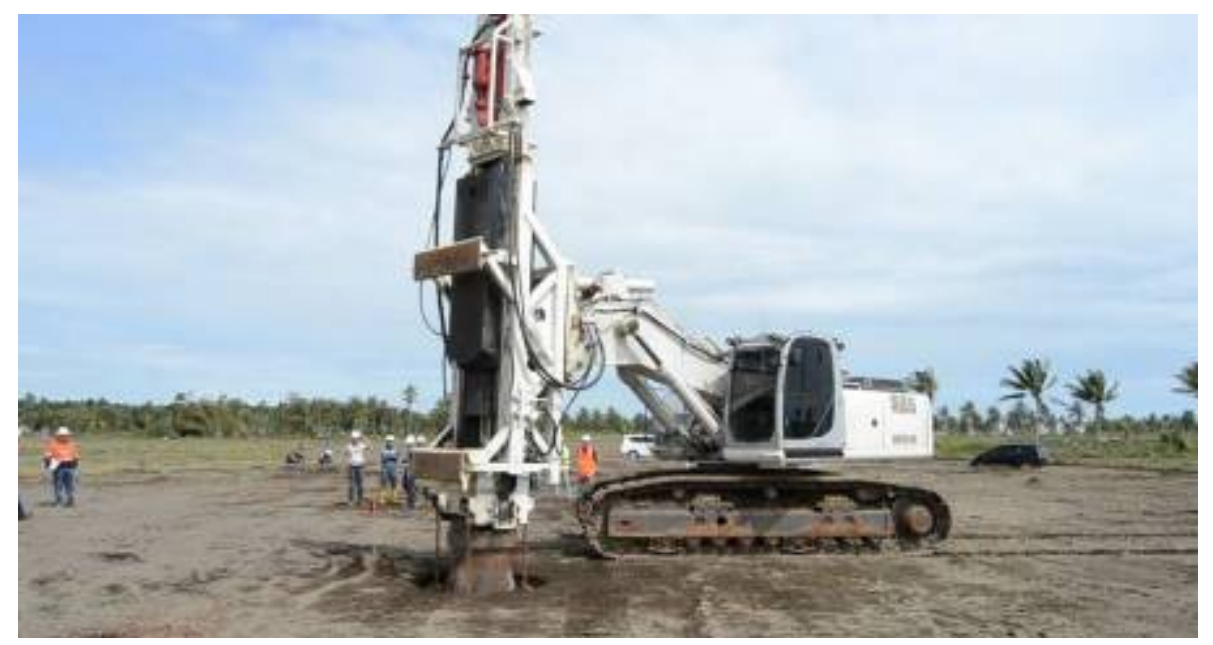

Gambar 5. Denah pekerjaan bandara [4]

Berat hammer yang digunakan yaitu sebesar 9 ton, sedangkan tinggi jatuhnya yaitu setinggi $1.2 \mathrm{~m}$. Pola tumbukan digunakan yaitu pola segitiga (triangular pattern) untuk tumbukan primer dan pola segienam untuk tumbukan sekunder seperti yang ditunjukan pada Gambar 6. Jumlah tumbukan ditentukan dari besar penurunan dan jumlah tumbukan maksimum. Apabila penurunan akhir telah mencapai kurang dari $10 \mathrm{~cm}$ atau jumlah tumbukan sudah mencapai 60 tumbukan, maka tumbukkan dihentikan. Kriteria tersebut menyebabkan berbedanya jumlah tumbukan di setiap titik seperti yang ditunjukkan pada Gambar 7. Pada pelaksanaan RIC, area terminal dibagi menjadi 30 bagian dan setiap bagian dilakukan pengujian SPT post-RIC yang ditunjukkan pada Gambar 8. 


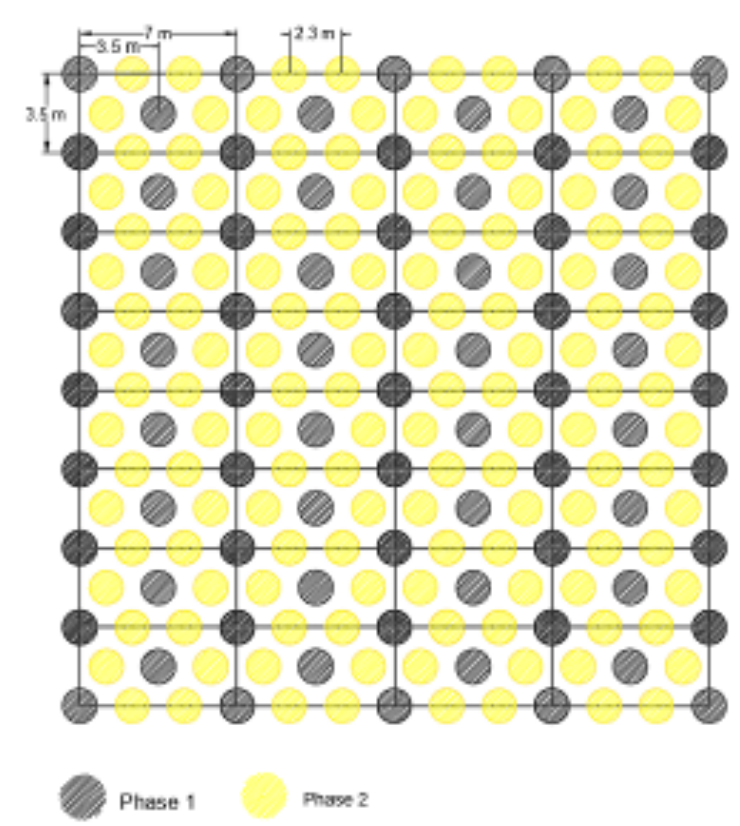

Gambar 6 Pola tumbukan RIC untuk area terminal

\begin{tabular}{|c|c|c|c|c|c|c|c|c|c|}
\hline DESCRIPTION & X-Center & Y-Center & LAYER & COMPACTIONDATE & BLOWCOUNT & $\begin{array}{l}\text { FINALSET } \\
\mathrm{mm}\end{array}$ & $\begin{array}{l}\text { DEEPTOTAL } \\
\mathrm{mm}\end{array}$ & $\begin{array}{l}\text { ENERGYTOTAL } \\
\text { MNm }\end{array}$ & STOPCODE \\
\hline & 396370.8034 & 9126604.7369 & $1-P$ & $6 / 23 / 2018$ 11:22 & 51 & 9.07 & 930.40 & 5.40 & $\mathrm{~S}$ \\
\hline & 396364.2256 & 9126607.1310 & $1-P$ & $6 / 23 / 201811: 26$ & 50 & 9.67 & 787.53 & 5.30 & $S$ \\
\hline & 396368.1130 & 9126607.5784 & $1-P$ & $6 / 23 / 2018$ 11:34 & 47 & 9.67 & 727.77 & 4.98 & $S$ \\
\hline & 396372.0005 & 9126608.0258 & $1-\mathrm{P}$ & $6 / 23 / 2018$ 11:43 & 23 & 9.74 & 274.25 & 2.44 & S \\
\hline & 396365.4226 & 9126610.4199 & $1-\mathrm{P}$ & $6 / 23 / 201811: 49$ & 41 & 9.74 & 655.47 & 4.34 & $S$ \\
\hline & 396369.3101 & 9126610.8673 & $1-\mathrm{P}$ & $6 / 23 / 201811: 54$ & 43 & 9.74 & 747.64 & 4.56 & $S$ \\
\hline & 396373.1975 & 9126611.3147 & $1-\mathrm{P}$ & $6 / 23 / 2018$ 11:58 & 32 & 12.54 & 655.02 & 3.39 & $S$ \\
\hline & 396366.6197 & 9126613.7088 & $1-\mathrm{P}$ & $6 / 23 / 2018$ 12:00 & 38 & 8.96 & 672.06 & 4.03 & $S$ \\
\hline & 396370.5072 & 9126614.1562 & $1-\mathrm{P}$ & $6 / 23 / 201812: 03$ & 41 & 9.07 & 723.09 & 4.34 & $\mathrm{~S}$ \\
\hline & 396374.3946 & 9126614.6036 & $1-\mathrm{P}$ & $6 / 23 / 2018$ 12:06 & 41 & 9.74 & 718.93 & 4.34 & S \\
\hline & 396367.8168 & 9126616.9978 & $1-P$ & $6 / 23 / 201812: 10$ & 23 & 9.97 & 355.39 & 2.44 & S \\
\hline & 396371.7042 & 9126617.4452 & $1-P$ & $6 / 23 / 201812: 12$ & 32 & 9.74 & 565.04 & 3.39 & $\mathrm{~S}$ \\
\hline & 396375.5917 & 9126617.8926 & $1-P$ & $6 / 23 / 201812: 17$ & 36 & 9.37 & 656.68 & 3.81 & $S$ \\
\hline & 396369.0138 & 9126620.2867 & $1-\mathrm{P}$ & $6 / 23 / 2018$ 12:20 & 29 & 9.67 & 522.05 & 3.07 & $S$ \\
\hline & 396372.9013 & 9126620.7341 & $1-\mathrm{P}$ & $6 / 23 / 201812: 23$ & 34 & 9.90 & 598.73 & 3.60 & $S$ \\
\hline & 396376.7888 & 9126621.1815 & $1-\mathrm{P}$ & $6 / 23 / 2018$ 12:26 & 37 & 9.82 & 663.56 & 3.92 & S \\
\hline
\end{tabular}

Gambar 7. Contoh hasil monitoring jumlah tumbukan pada pekerjaan RIC di area terminal [11]

Berdasarkan hasil monitoring pekerjaan RIC dilapangan didapat variasi jumlah tumbukan antara 2 60 tumbukan per titik, sehingga untuk mempermudah analisis digunakan jumlah tumbukan maksimum, minimum dan rata-rata di setiap area. Energi tumbukan pada masing-masing area dihitungan dengan menggunakan Persamaan 1 di bawah ini [5].

$$
A E=\frac{N_{d} W_{t} H_{d}}{A_{\infty}}
$$

Pada persamaan energi yang digunakan terdapat nilai Ae dimana nilai tersebut merupakan luas ekivalen yang tergantung dari pola tumbukan. Pola tumbukan yang digunakan untuk perbaikan tanah menggunakan RIC yaitu segi tiga untuk phase pertama (primer) dan segienam untuk phase kedua (sekunder), sehingga Ae yang digunakan yaitu $0.867 \mathrm{~s}^{2}$ untuk pola segitiga dan $1.299 \mathrm{~s}^{2}$ untuk pola segienam seperti yang ditunjukkan pada Gambar 9. Perhitungan energi akibat tumbukan dari RIC di area terminal SPT 15 ditunjukkan pada Tabel 3. 


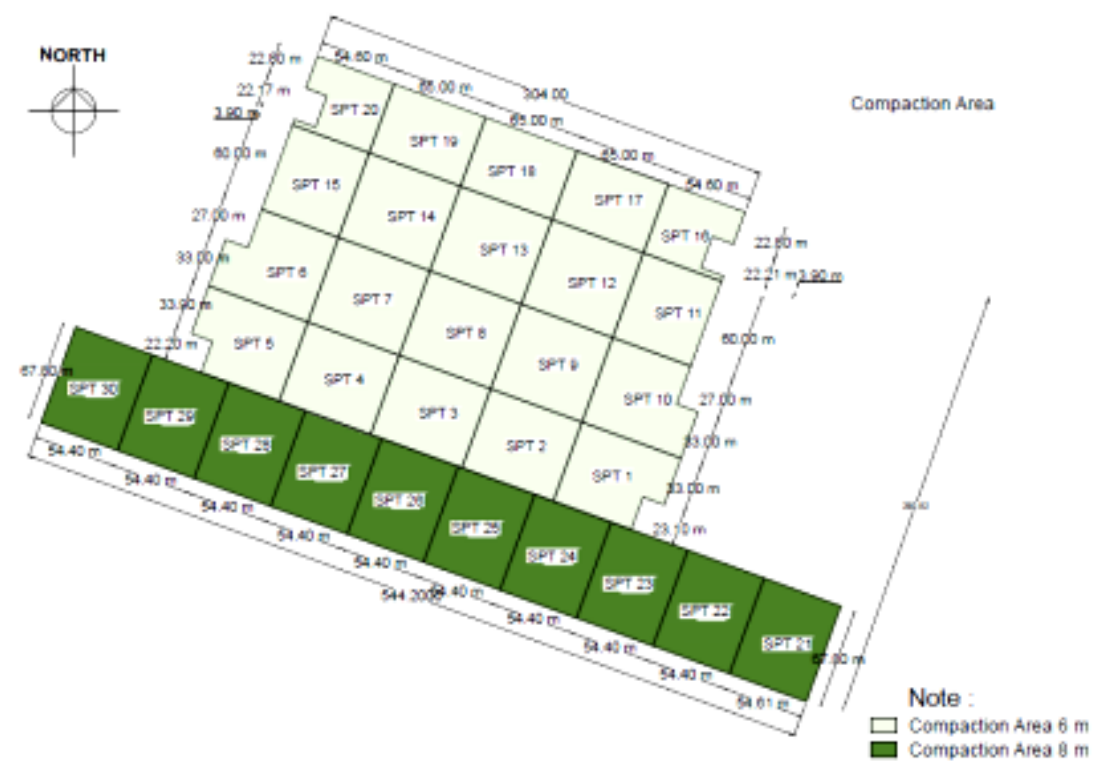

Gambar 8 Pembagian area terminal post - RIC [11]

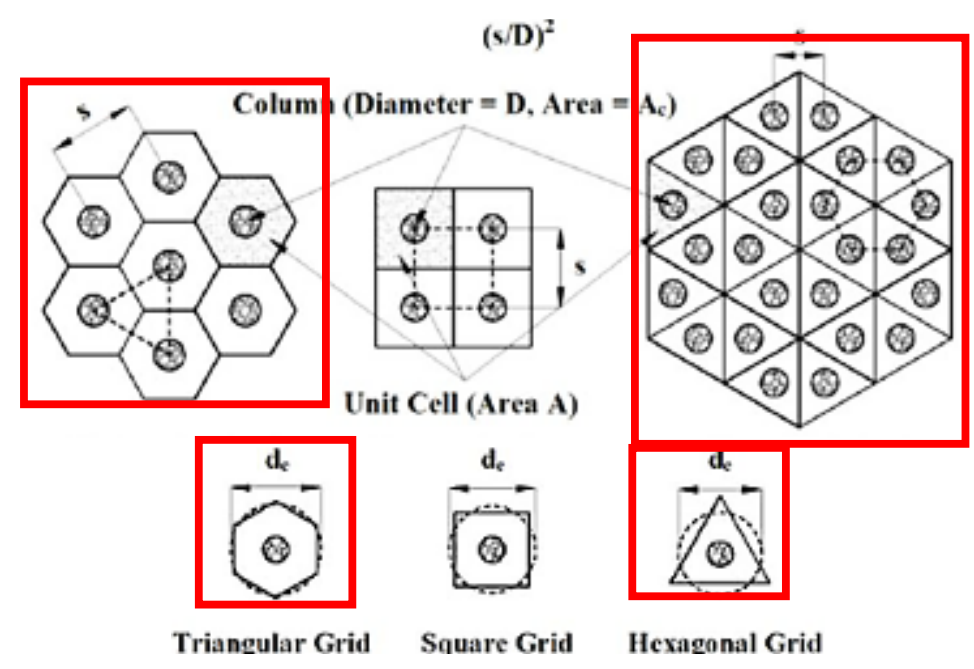

Gambar 9. Pola tumbukan segitiga dan segienam dan nilai Ae untuk metode perbaikan RIC di area terminal [12]

Tabel 3. Konfigurasi Tumbukan dengan RIC di SPT 15

\begin{tabular}{lcccccc}
\hline \multirow{2}{*}{ Uraian } & \multicolumn{2}{c}{ Uper Bound } & \multicolumn{2}{c}{ Lower Bound } & \multicolumn{2}{c}{ Average Bound } \\
\cline { 2 - 8 } & Fase 1 & Fase 2 & Fase 1 & Fase 2 & Fase 1 & Fase 2 \\
\hline Jumlah Tumbukan $[\mathrm{N}]$ & 41 & 44 & 2 & 1 & 28 & 15 \\
\hline Berat Tamper [ton] & 9.00 & 9.00 & 9.00 & 9.00 & 9.00 & 9.00 \\
\hline Tinggi Jatuh [m] & 1.20 & 1.20 & 1.20 & 1.20 & 1.20 & 1.20 \\
\hline Spasi $[\mathrm{m}]$ & 3.50 & 2.33 & 3.50 & 2.33 & 3.50 & 2.33 \\
\hline Nomor pass & 1 & 1 & 1 & 1 & 1 & 1 \\
\hline $\begin{array}{l}\text { Average Applied } \\
\left.\text { Energy[tm } / \mathrm{m}^{2}\right]\end{array}$ & 41.69 & 67.38 & 1.76 & 1.53 & 24.69 & 22.97 \\
\hline $\begin{array}{l}\text { Total Applied } \\
\text { Energy }\left[\mathrm{tm} / \mathrm{m}^{2}\right]\end{array}$ & $\mathbf{1 0 9 . 0 8}$ & $\mathbf{3 . 2 9}$ & $\mathbf{4 7 . 6 6}$ \\
\hline $\begin{array}{l}\text { Total Applied } \\
\text { Energy }\left[\mathrm{kJ} / \mathrm{m}^{2}\right]\end{array}$ & $\mathbf{1 0 6 9 . 7 1}$ & $\mathbf{3 2 . 3 1}$ & $\mathbf{4 6 7 . 3 8}$ \\
\hline
\end{tabular}

Rekayasa Hijau - 89 


\section{HASIL DAN PEMBAHASAN}

Hasil analisis data lapangan sebelum dan setelah perbaikan menggunakan Metode RIC ditunjukkan pada Gambar 10 dan Gambar 11 di bawah ini. Pada Tabel 4 menujukkan nilai rata-rata NSPT dari setiap titik dan kedalaman uji SPT.

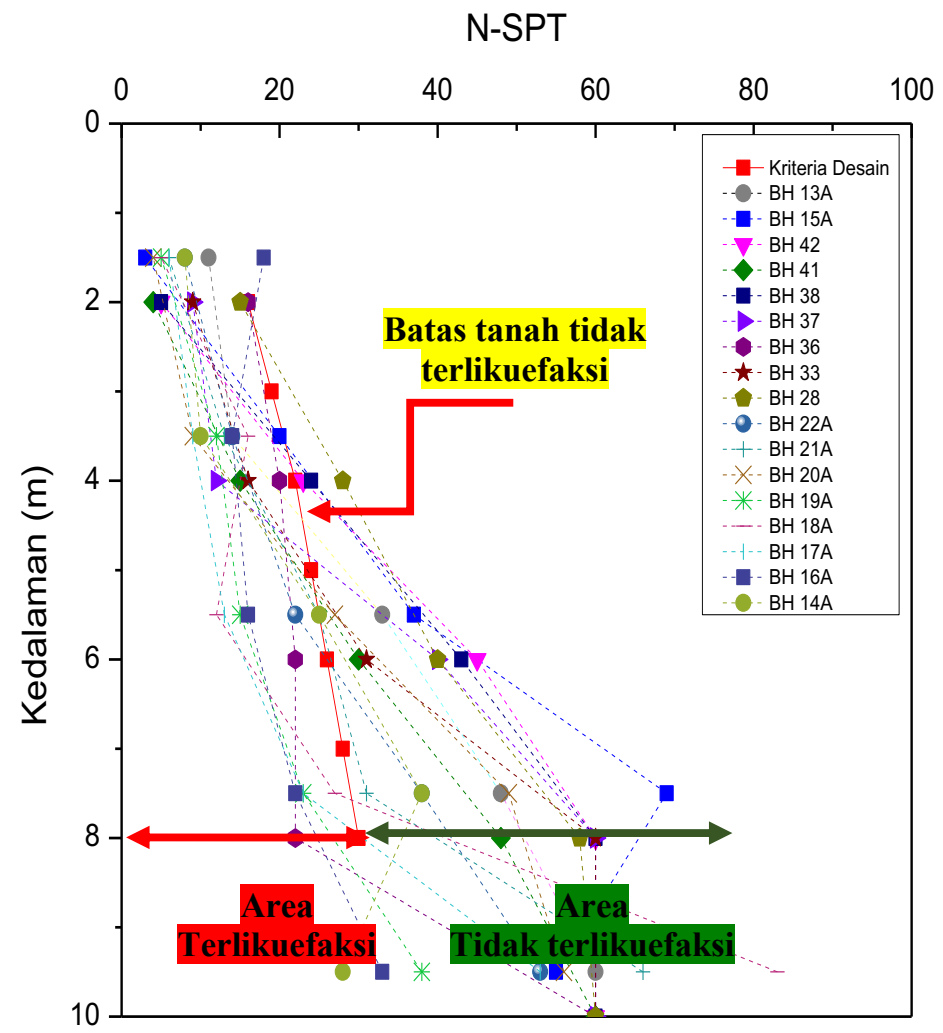

Gambar 10. Grafik hubungan antara NSPT dengan kedalaman sebelum RIC di 17 titik. N-SPT

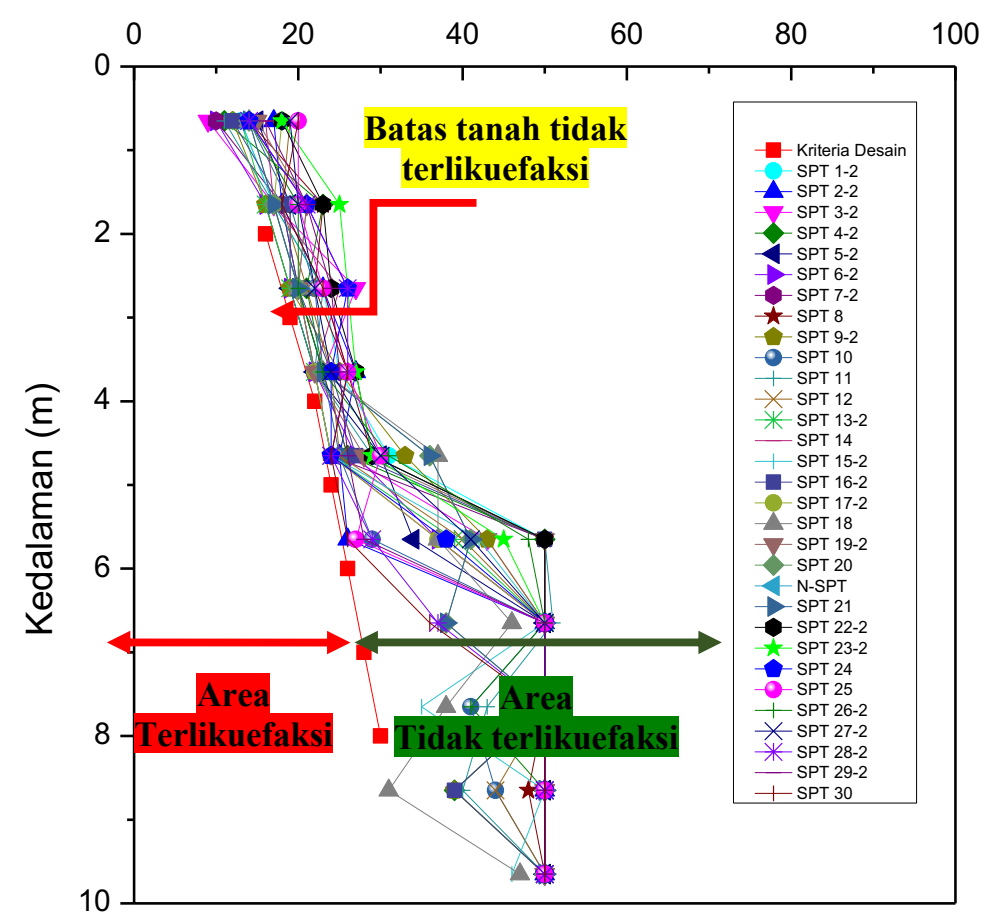

Gambar 11. Grafik hubungan antara NSPT dengan kedalaman setelah RIC di 30 titik. 
Tabel 4. Kenaikan Rata-rata Nilai SPT Setelah Perbaikan Menggunaka RIC

\begin{tabular}{cccc}
\hline Kedalaman & $\begin{array}{c}\text { Rata-rata SPT } \\
\text { sebelum RIC }\end{array}$ & $\begin{array}{c}\text { Rata-rata SPT } \\
\text { setelah RIC }\end{array}$ & $\begin{array}{c}\text { Kenaikan } \\
\text { Rata-rata SPT }\end{array}$ \\
\cline { 1 - 1 } $\mathbf{2}$ & 8 & 20 & 12 \\
\hline $\mathbf{4}$ & 15 & 25 & 10 \\
\hline $\mathbf{6}$ & 25 & 43 & 17 \\
\hline $\mathbf{8}$ & 38 & 49 & 11 \\
\hline $\mathbf{1 0}$ & 47 & 50 & 3 \\
\hline $\mathbf{1 2}$ & 50 & 50 & 0 \\
\hline $\mathbf{1 4}$ & 50 & 50 & 0 \\
\hline $\mathbf{1 6}$ & 50 & 50 & 0 \\
\hline $\mathbf{1 8}$ & 50 & 50 & 0 \\
\hline $\mathbf{2 0}$ & 50 & 50 & 0 \\
\hline $\mathbf{2 2}$ & 50 & 50 & 0 \\
\hline $\mathbf{2 4}$ & 50 & 50 & 0 \\
\hline $\mathbf{2 6}$ & 50 & 50 & 0 \\
\hline $\mathbf{2 8}$ & 50 & 50 & 0 \\
\hline $\mathbf{3 0}$ & 50 & 50 & \\
\hline
\end{tabular}

Perbandingan umum dari nilai SPT sebelum dan setelah perbaikan tanah dapat menentukan apakah metode tersebut efektif digunakan. Hasil pengujian SPT kondisi sebelum perbaikan menggunakan RIC, menunjukkan bahwa rata-rata hingga kedalaman $6-8 \mathrm{~m}$ nilai SPT yang didapat kurang dari SPT kriteria desain seperti yang ditunjukkan pada Tabel 2 di atas, sehingga tanah berpotensi likuefkasi dan perlu adanya upaya perbaikan tanah. Sedangkan, hasil pengujian SPT di lapangan setelah tanah diperbaiki dengan RIC menunjukkan bahwa nilai SPT telah melawati nilai kriteria desain pada seluruh kedalaman, sehingga tanah tidak lagi berpotensi likuefaksi. Hasil tersebut menunjukkan bahwa RIC bekerja dengan sangat baik padda tanah pasir yang berpotensi likuifkasi.

Rekapitulasi plot nilai SPT untuk kondisi sebelum dan setelah diperbaiki menggunakan metode RIC di area terminal ditunjukkan pada Gambar 10 dan Gambar 11. Pada grafik ditunjukkan garis kriteria desain, jika hasil plot berada di sisi kiri dari kriteria desain maka tanah berpotensi likuefkasi, sedangkan jika berada di sisi kanan tanah sudah tidak berpotensi terlekuefaksi.

Pada Gambar 10 di atas, kondisi tanah sebelum perbaikan menggunakan RIC menujukkan rata-rata NSPT bernilai 8 - 15 pada kedalaman $2-4 \mathrm{~m}$. Sedangkan pada Gambar 11 menujukkan bahwa pada kondisi setelah dilakukannya perbaikan menggunakan RIC, rata-rata NSPT meningkat menjadi 20 25. Berdasarkan data lapangan tersebut terjadi kenaikan nilai SPT sebesar $10-12$ setelah tanah diperbaiki menggunakan RIC, sehingga nilai SPT dapat memenuhi kriteria desain dan dapat mengurangi potensi likuefaksi. Rekapitulasi kenaikan NSPT pada setiap kedalaman ditunjukkan pada Tabel 4 .

\section{KESIMPULAN}

Hasil pemadatan di lokasi pembangunan Bandara New Yogyakarta International Airport, menunjukkan bahwa metode Rapid Impact Compaction dapat meningkatkan daya dukung tanah hingga memenuhi kriteria desain yang disyaratkan oleh proyek dengan konfigurasi desain RIC menggunakan tamper berdiameter $1.5 \mathrm{~m}$, tinggi jatuh $1.2 \mathrm{~m}$, dengan pola segitiga (primer) dan segienam (sekunder). Berdasarkan penyelidikan tanah di lapangan yaitu uji SPT, metode Rapid Impact 
Compaction dapat diterapkan untuk tanah pasir lepas yang berpotensi likuifaksi hingga kedalaman 6 $8 \mathrm{~m}$. Hasil analisis pada kedalaman $6-8 \mathrm{~m}$ menunjukkan adanya kenaikan nilai rata-rata SPT sebelum dan setelah perbaikan yaitu sebesar $10-12$. Hasil pengujian SPT setelah perbaikan pun menunjukkan bahwa nilai SPT telah melebihi kriteria desain sehingga dapat mengurangi potensi likuefkasi.

Ketinggian muka air tanah tidak mencegah metode ini dalam memperbaiki tanah, akan tetapi dapat mereduksi energi pemadatan untuk memadatkan lapisan yang lebih dalam. Menurut Sandelin [9] Tahun 2018 bahwa hasil pemadatan akan lebih baik jika dilakukan proses dewatering terlebih dahulu sebelum perbaikan tanah.

\section{DAFTAR PUSTAKA}

[1] Adam, D., Adam, C., Faulkner, F. J., Paulmichi, I. (2011). "Vibration emission induced by Rapid Impulse Compaction" Proc. 8th International Conference on Structural Dynamics, Leuven, Belgium., pp. 914-921.

[2] Han, Jei. (2015). Principles and Pratice of Ground Improvement, John Wiley \& Sons., Hoboken, New Jersey, Canada.

[3] Faulkner, F. J., Adam, C., Paulmichi, I., Adam, D., Furpass, J. (2010). "Rapid Impact Compaction for Middle-Deep Improvement of The Groud - Numerical and Experimental Investigations" From Research to Design in European Practice, Bratislava, Slovak Repubic.

[4] Geoinventions, (2018). Laporan Hasil Pengujian RIC, 2018.

[5] Sandelin M. (2018), Evaluation of Dynamic Compaction Method and Rapid Impact Compaction Method for Soil Improvemnet. Master's Thesis. Aalto Iniversity School of Engineering.

[6] Cetin, K.O., Seed, R.B., Kiureghian, A.D., Tokimatsu, K., Harder Jr. L.F., Kayen, R.E., Moss, R.E.S. (2004). Standard Penetration Test-Based Probabilistic and Deterministic Assessment of Seismic Soil Liquefaction Potential. Journal of Geotechnical and Geoenvironmental Engineering, 130, $1314-1340$.

[7] Tim PP (Persero) Tbk., (2018). Deep Soil Improvement $0-8 m$ dengan Metode Dynamic Compaction. PT. PP (Persero) Tbk.

[8] Promisco, (2018). Data pengujian lapangan berupa layout pekerjaan,

[9] PT. PP Persero Tbk, (2018). Data pengujian lapangan 2018.

[10] Tarawneh, B., Hakam, Y. (2017). "Perfomance of Rapid Impact Compaction as a Middle-Deep Ground Improvement Technique" Proc. 19th International Conference on Soil Mechanics and Geotehcnical Engineering, Seoul, South Korea., pp. 2623-2626.

[11] Tim PT. Vantage Infrasturcutes Indonesia, (2018). Laporan Faktual Final RIC Bandar Udara Baru Internasional Yogyakarat - Area Terminal. PT. VII.

[12] Sahadewa, A. (2017). Catatan Kuliah Perbaikan Tanah Vibro Compaction. 